\title{
Do Library Fines Work?: Analysis of the Effectiveness of Fines on Patron's Return Behavior at Two Mid-sized Academic Libraries ${ }^{\text {th }}$
}

\author{
Jan S. Sung ${ }^{\mathrm{a}, *}$, Bradley P. Tolppanen ${ }^{\mathrm{b}, 1}$ \\ a University of Hawaii at Manoa Library, 2550 McCarthy Mall, Honolulu, HI 96822, USA \\ b Eastern Illinois University, 600 Lincoln Ave., Charleston, IL 61920, USA
}

\section{A R T I C L E I N F O}

Article history:

Received 11 February 2013

Accepted 12 August 2013

Available online 3 September 2013

Keywords:

Library fines

Statistical analysis

Effectiveness

\section{A B S T R A C T}

Data on library fines imposed at Eastern Illinois University and the University of Hawaii at Manoa was extracted and compared to determine whether fines had an impact on the patron's return behavior. The results indicated that fines as well as patron group status (undergraduate, graduate, faculty) have an impact on the patron's return behavior.

(C) 2013 Elsevier Inc. All rights reserved.

\section{INTRODUCTION}

Library fines and fees for overdue books have been a longstanding and widespread practice in libraries. These financial penalties have, in general, been considered to help ensure that users return borrowed books before the due dates or at least shortly thereafter. However, no study has been performed to prove that library fines actually make a difference in the patron's return behavior. The best way to see the effectiveness of fines is to compare the return rates between patron groups, both with and without fines. The purpose of this study is to compare two academic libraries, Eastern Illinois University (EIU) library and the University of Hawaii at Manoa (UHM) library, in order to quantify the effectiveness of fines and its impact on the patron's return behavior.

\section{LITERATURE REVIEW}

A literature search using the Library Literature E' Information Science Index and Library, Information Science E Technology Abstracts databases was completed in order to situate this study in the published literature. A combined search of the databases using the keyword term "library fines" generates 790 results. A further search using the same term as a subject search narrows the results to 210 . Combining the search with the terms "behavior," "return," or "library users" does not return a study that examines the return rates as the result of the imposition of fines

\footnotetext{
it The part of data was presented at the ALA 2010 Annual Conference: "Myth Busting: Using Data to Challenge Assumptions" (June 27, 2010, Washington DC).

* Corresponding author. Tel.: +1 808956 2468; fax: + 18089567109.

E-mail addresses: jansung@hawaii.edu (J.S. Sung), bptolppanen@eiu.edu

(B.P. Tolppanen)

1 Tel.: +1 217581 6006; fax: +12175816066.
}

and fees. The results confirm the observation made by Pixey Anne Mosley in her 2004 article that the literature on fines is "rather sparse." This study will attempt to fill this void in the published literature by quantifying the effectiveness of fines on patron's return behavior.

The dominant theme in the literature on fines and fees is their controversial nature and whether libraries should maintain the practice. Mitchell and Smith (2005) point out that fines usually aid in the return of books. Critics, however, believe that there is little evidence that fines are any more effective at minimizing overdue books than are reminder notices (Mitchell \& Smith, 2005). Furthermore, opponents of fines believe them to be unethical and not worth the harmful public relations aspects. Fines and fees can also be considered to be an economic barrier to information access and as such, the American Library Association (1996) urges libraries to "resist the temptation to impose user fees to alleviate financial pressures." However, collection of fines can generate substantial income in a library (Ching, Tai, Pong, \& Cheng, 2009). With the debate between a "fines" or "no-fines" policy, articles in the published literature feature such libraries as New York University, Texas A\&M University, and Swarthmore College that have respectively eliminated daily fining, adopted a multi-layered approach, and introduced a penalty point system to better manage their reserve books (Rupp, Sweetman, \& Perry, 2010).

\section{BACKGROUND}

Booth Library provides library services for Eastern Illinois University (EIU), located in Charleston, Illinois. The university, a medium-sized institution, has a student population of 10,000 undergraduates, 1500 graduate students, and 900 faculty members. The library holdings consist of over 1.7 million cataloged books. During the Fiscal Year 2012, Booth Library had a total circulation of 114,677. 
The University of Hawaii at Manoa (UHM) library provides library services for the university, located in the Manoa Valley in Honolulu, Hawaii. The university has a student population of 14,000 undergraduate students, 6000 graduate students, and 1700 faculty members. The library holdings consist of over 3.4 million cataloged books. During the Fiscal Year 2012, the library had a total circulation of 164,980.

\section{OVERVIEW OF FINES POLICY}

At Booth Library (EIU) one courtesy notice is sent to patrons three days before a book is due and three overdue notices at one day overdue, ten days overdue, and twenty-one days overdue. Undergraduate students are charged $\$ 0.25$ per day for each overdue book with a maximum fine of $\$ 10$ per book (see Table 1). Overdue fines of under $\$ 2.50$ are waived, which in effect provides a ten-day grace period. This grace period, however, is not publicized to the students. Undergraduates are able to borrow books for four weeks with ten renewals.

Fines were not imposed on EIU graduate students until mid-2006. Until that point, graduate students were able to borrow books for 16 weeks, which was the same amount of time as EIU faculty members. Long overdue books generated a lost book charge plus a \$15 processing fee for graduate students. Students with outstanding fines and fees were prohibited from registering for the subsequent semester. Upon return, the lost book charge was waived but students were still responsible for the processing fee. Starting in the Fall of 2006, the fine and loan policy for EIU graduate students were changed to match the undergraduate students' policy. Overdue fines were imposed and the loan period was reduced to four weeks. The impact of these changes was clearly evident. The graduate student advisory group immediately contacted the library to request an increase in loan period, but they interestingly did not mention fines. The loan period for graduate students was increased to eight weeks in the Fall of 2007, but the fine system remained in place.

Overdue fines are not imposed on EIU faculty members. Any books held too long after the due dates by a faculty member will be treated as lost and a lost book charge and a processing fee will be posted. However, all charges are waived upon the return of the library books.

The University of Hawaii at Manoa (UHM) library sends one courtesy notice three days before a book is due and two overdue notices at one day overdue and fourteen days overdue. In terms of fines and fees, there is no distinction amongst different patron groups. All patron groups are charged $\$ 0.25$ per day for each overdue book without any grace period. Overdue fines are capped at a maximum of $\$ 10$ per book (see Table 1 ). Those with fines over $\$ 10$ will be blocked from the online access to the e-resources and unable to register courses. Average return rates before due dates and after overdue notices were sent are shown in Table 2.

\section{RESEARCH QUESTIONS}

The present study is intended to investigate the possible explanations of the effects of fines or group differences on book return behaviors.

Table 1

Loan periods and fines and fees schedule

\begin{tabular}{|c|c|c|c|}
\hline & Faculty & Graduate & Undergraduate \\
\hline \multirow[t]{5}{*}{ EIU } & $4 \mathrm{M} / 10 \mathrm{R}$ & $4 \mathrm{M} / 10 \mathrm{R}$ until Fall 06 & $1 \mathrm{M} / 10 \mathrm{R}$ \\
\hline & & $1 \mathrm{M} / 10 \mathrm{R}$ (Fall 06-Spring 07) & \\
\hline & & $2 \mathrm{M} / 10 \mathrm{R}$ (Fall 07) & \\
\hline & No fines or fees & No fines or fees until Summer 06 & $\$ .25 /$ day with 10 day \\
\hline & & $\begin{array}{l}\text { Since Fall } 06 \$ .25 / \text { day with } \\
10 \text { day grace period }\end{array}$ & grace period \\
\hline \multirow[t]{2}{*}{ UHM } & $6 \mathrm{M} / 99 \mathrm{R}$ & $3 \mathrm{M} / 5 \mathrm{R}$ & $1 \mathrm{M} / 5 \mathrm{R}$ \\
\hline & $\begin{array}{l}\$ .25 / \text { day without } \\
\text { grace period }\end{array}$ & $\$ .25 /$ day without grace period & $\begin{array}{l}\$ .25 / \text { day without } \\
\text { grace period }\end{array}$ \\
\hline
\end{tabular}

$\mathrm{M}=$ months, $\mathrm{R}=$ renewals, EIU = Eastern Illinois University, $\mathrm{UHM}=$ University of Hawaii at Manoa.
When comparing these two mid-sized institutions, other factors that might impact the return rates of books, such as the need of books for prolonged periods for research or the maturity of the students are considered the same at both places. Additionally, the courtesy and overdue notice policies are very similar at both institutions. With these factors being similar at both institutions, the authors formulated five hypotheses to test against the data.

Hypothesis 1. There is no difference in return rates before due dates among the UHM patron groups because the fine policy is the same for all patron groups. The hypothesis considers impact of group differences on book return behavior before due dates.

Hypothesis 2. Before 2006, the EIU undergraduate students' return rates before due dates should be the highest among the three EIU groups because this was the only group which had overdue fines. Also, during this period, there should be no group difference of return rates before due dates between EIU faculty and EIU graduate students (both groups had no overdue fines). The hypothesis seeks to find the impact of fines on different patron groups.

Hypothesis 3. EIU graduate students' return rates before due dates was lower for 2002-2006 than for 2007-2011. The hypothesis seeks to test the impact of the change of fine policy on patron's book return behavior; no fines were applied for EIU graduate students for 2002-2006. Starting in Fall 2006, fines were applied for EIU graduate students.

Hypothesis 4. UHM undergraduate students' return rates before due dates is higher than that of EIU undergraduate students. Fine policies for both UHM undergraduate students and EIU undergraduate students are the same except that there is an unpublicized ten-day grace period for EIU undergraduate students. The hypothesis seeks to test the effect of the grace period.

Hypothesis 5. UHM faculty's return rates before due dates is higher than that of EIU faculty. The hypothesis seeks to test the impact of fine policy differences on patron's book return behavior on similar patron groups. There are overdue fines for UHM faculty while there are no overdue fines and no penalty for returning books claimed long overdue for EIU faculty.

\section{METHODOLOGY}

Data for the number of books returned before due dates, the number of books returned after overdue notices were sent, and the total number of books borrowed by different groups (undergraduate, graduate, and faculty) at EIU and UHM were extracted for the period from Fall 2002 to Spring 2011. Both libraries have been using the same integrated library system (Voyager). Therefore, the method of data extraction was exactly the same in both libraries. In order to compare data among/ between groups, return rates before due dates and after overdue notices were sent were calculated for each semester (July-Dec and Jan-June) by each group; where return rates were defined as the number of books returned (before due dates and after overdue notices were sent) divided by the total number of books charged for each semester by each group.

Due to a lack of study on fine policy and patron's book return behavior, especially with no statistical analysis previously performed, the authors relied on the broader literature on statistics. Analysis of variances (ANOVA), the common method to compare group differences, was performed to test if any difference is beyond chance using SPSS version 19.0 (Statistical Package for Social Science) (Field, 2009). ANOVA is expressed with F-ratio (sum of variance occurred by condition divided by sum of variance occurred by errors). $p$ value shows the likelihood of happening of the F-ratio. The present study uses $p<.01$ as the level of statistical significance. 
Table 2

Average return rate before due date and after overdue notices sent

\begin{tabular}{|c|c|c|c|c|c|c|c|c|c|c|c|c|}
\hline & \multicolumn{4}{|l|}{ Faculty } & \multicolumn{4}{|c|}{ Graduate students } & \multicolumn{4}{|c|}{ Undergraduate students } \\
\hline & Before due & 1st ODN & 2nd ODN & 3rd ODN & Before due & 1st ODN & 2nd ODN & 3rd ODN & Before due & 1st ODN & 2nd ODN & 3rd ODN \\
\hline EIU & $81.1 \%$ & $10.4 \%$ & $3.3 \%$ & $5.2 \%$ & $92.8 \%$ & $4.6 \%$ & $1.0 \%$ & $1.6 \%$ & $89.5 \%$ & $7.2 \%$ & $1.5 \%$ & $1.8 \%$ \\
\hline UHM & $95.7 \%$ & $3.3 \%$ & $1.0 \%$ & - & $93.9 \%$ & $4.6 \%$ & $1.4 \%$ & - & $90.4 \%$ & $7.4 \%$ & $2.1 \%$ & - \\
\hline
\end{tabular}

EIU = Eastern Illinois University, UHM = University of Hawaii at Manoa, ODN = overdue notice.

\section{RESULTS AND DISCUSSION}

\section{HYPOTHESIS 1}

There is no difference in return rates before due dates among the University of Hawaii at Manoa's (UHM) patron groups because the fine policy is the same to all patron groups.

The findings did not support the hypothesis. Despite having a consistent fines policy across all patron groups at UHM, there were still statistically significant differences in the return rates, with undergraduates being the poorest and faculty being the best to return books on time: the average return rates before due dates were $90.4 \%, 93.9 \%$, and $95.7 \%$ respectively $(\mathrm{F}=112.1, p=000)$. With the fines policy the same, differences in the return rates can be ascribed to differences between the patron groups themselves, such as the responsibility and maturity of the borrower (Graphs 1 and 2).

The difference of loan policies among UHM patrons ( 1 month/5 renewals for undergraduate students; 3 months/5 renewals for graduate students; 6 months/99 renewals for faculty) may also be the explanation for these group differences (see Table 1). It would be interesting to test if these group differences disappear when the loan policy is the same for all three UHM groups.

\section{HYPOTHESIS 2}

Before 2006, EIU undergraduate students' return rates before due dates should be the highest among the three EIU groups because this was the only group which had overdue fines. Also, during this period, there should be no group difference of return rates before due dates between EIU faculty and EIU graduate students (both groups had no overdue fines).

The findings did not support this hypothesis. The means of return rates before due dates of EIU undergraduate students, graduate students, and faculty were $88.8 \%, 92.6 \%$, and $81.1 \%$ respectively. The group difference was statistically significant $(\mathrm{F}=171.4, p=.000)$. Interestingly, the EIU graduate students' return rates were much higher than that of the EIU faculty members when their fines and loan policy were the same during 2002-2006 (see Graph 3). This could be the result of lost book charges and processing fees that are imposed on both EIU graduate students and faculty members when books were deemed lost due to being overdue for an extended period. While all fines and fees are waived for faculty members upon the return of the books, graduate students were still responsible for the processing fees. Additionally, graduate students are not able to obtain their diploma until all borrowed books are returned and they have paid their fines or fees to the library (Graph 4).

On the other hand, EIU graduate students' return rates before due dates was even higher than that of EIU undergraduate students. Because graduate students are not fined for overdue books as long as the books are returned before they are considered lost, there must be some other explanation for the high return rates. The group difference still remained between EIU undergraduate students and graduate students after 2007 when fines were imposed for EIU graduate students (mean for EIU undergraduates $=90.2 \%$; mean for EIU graduates $=93.6 \%$ ). The maturity of the students may be one answer for the difference. Parental involvement in the undergraduate student's life may be another reason. In other words, fines accumulated for undergraduate students may be paid by their parents. If someone else pays the fine, students may act less responsible in their behavior. Nonetheless, even though the difference is statistically significant ( $F=106.3, p=.000)$, the difference is still relatively small (see Graph 3 ).

\section{HYPOTHESIS 3}

EIU graduate students' return rates before due dates was lower for 2002-2006 than for 2007-2011. Fine policies for EIU graduate students were changed drastically during the Fall semester of 2006. There were no fines for EIU graduate students before Fall 2006. Thus, this hypothesis

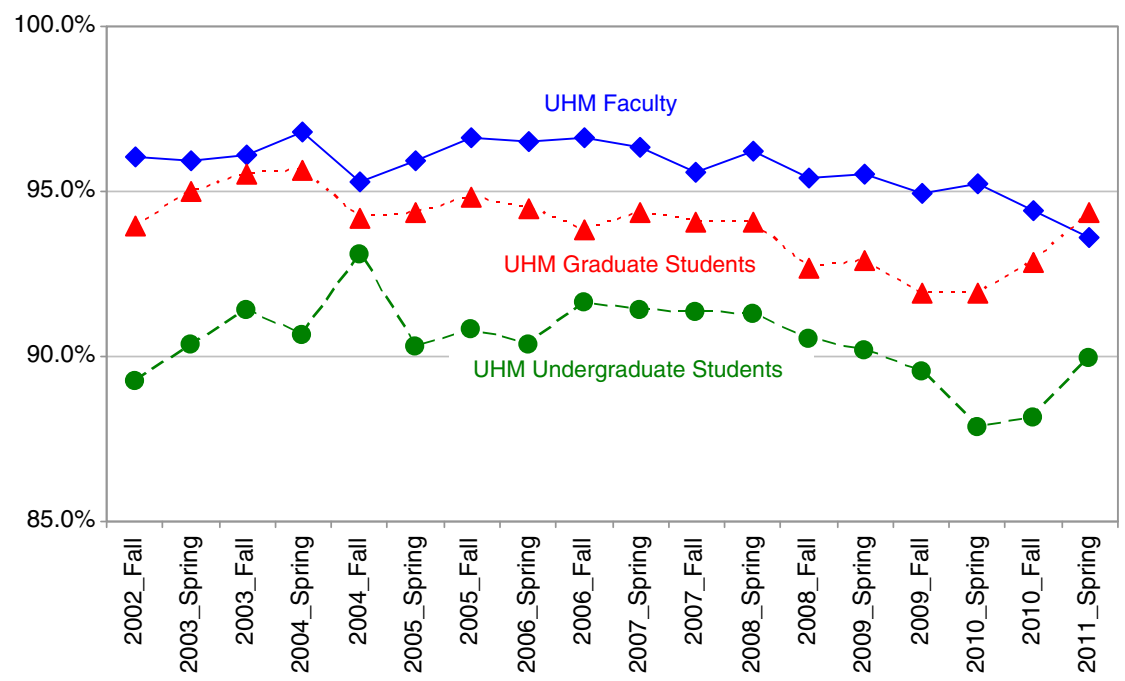

Graph 1. University of Hawaii at Manoa patron's book return rate before due date. 


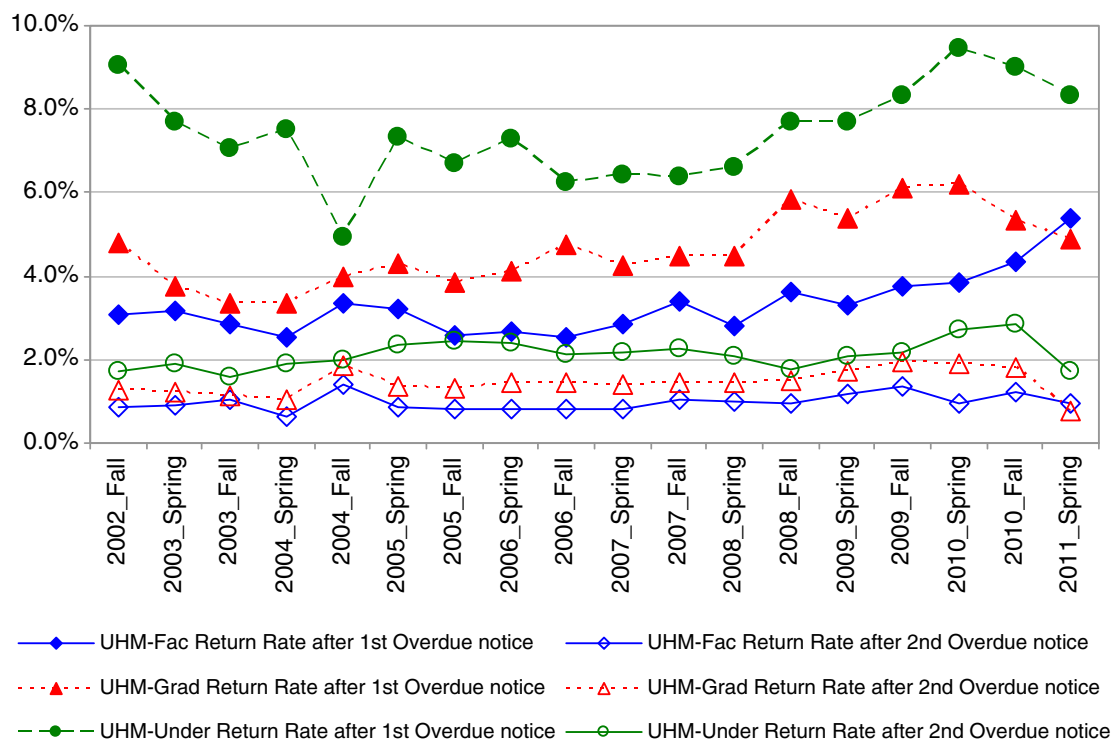

Graph 2. University of Hawaii at Manoa patron's book return rate after due date.

can test the impact of the change of fine policy on the patron's book return behavior.

The findings did not support this hypothesis. The mean return rate before due dates for the EIU graduate students for 2002-2006 was 92.6\%; for 2007-2011 it was 93.6\% (see Graph 3). The statistics did not show the significant difference $(F=5.75, p=.031)$. Even though EIU did not collect fines for EIU graduate students during 2002-2006, the library still imposed a lost book charge plus a processing fee of $\$ 15$ for long overdue books. Any charges to student accounts prohibited them from registering for the subsequent semester. Also, when lost books were returned, the lost book charge was dropped, but students were still responsible for the $\$ 15$ fee associated with the lost book. The required fee probably had an impact on whether they returned books on time. Thus, unless the collecting fines in itself was the goal of imposing the fines, there was no gain by imposing fines on this particular group.

\section{HYPOTHESIS 4}

UHM undergraduate students' return rates before due dates is higher than that of EIU undergraduate students because there is no grace period for UHM undergraduates. The fine policy for these two groups, UHM undergraduate students and EIU undergraduate students, are identical except that there is a ten-day grace period for EIU undergraduate students. Thus, if UHM undergraduate students return books on time greater than their counterpart, it can be accounted for by no grace period.

The findings did not support this hypothesis. The average return rates before due dates for EIU undergraduate students and UHM undergraduate students were $89.5 \%$ and $90.4 \%$ respectively (see Graph 5). Excluding the EIU faculty group, the EIU undergraduate students' return rates before due dates were surprisingly the lowest of all patron groups. The difference was not statistically significant $(\mathrm{F}=4.355, p=.044)$. The UHM undergraduate students returned $7.4 \%$ after the first overdue notice (7.2\% for EIU undergraduate students). EIU undergraduate students returned $98.2 \%$ within the grace period (see Table 2 ). The grace period used at EIU did not seem to have any adverse effect on the undergraduate students' return behavior. It may be because EIU does not advertise the existence of a grace period. It would be interesting to see if EIU undergraduate students maintain their book return behavior even when they know there is such a grace period.

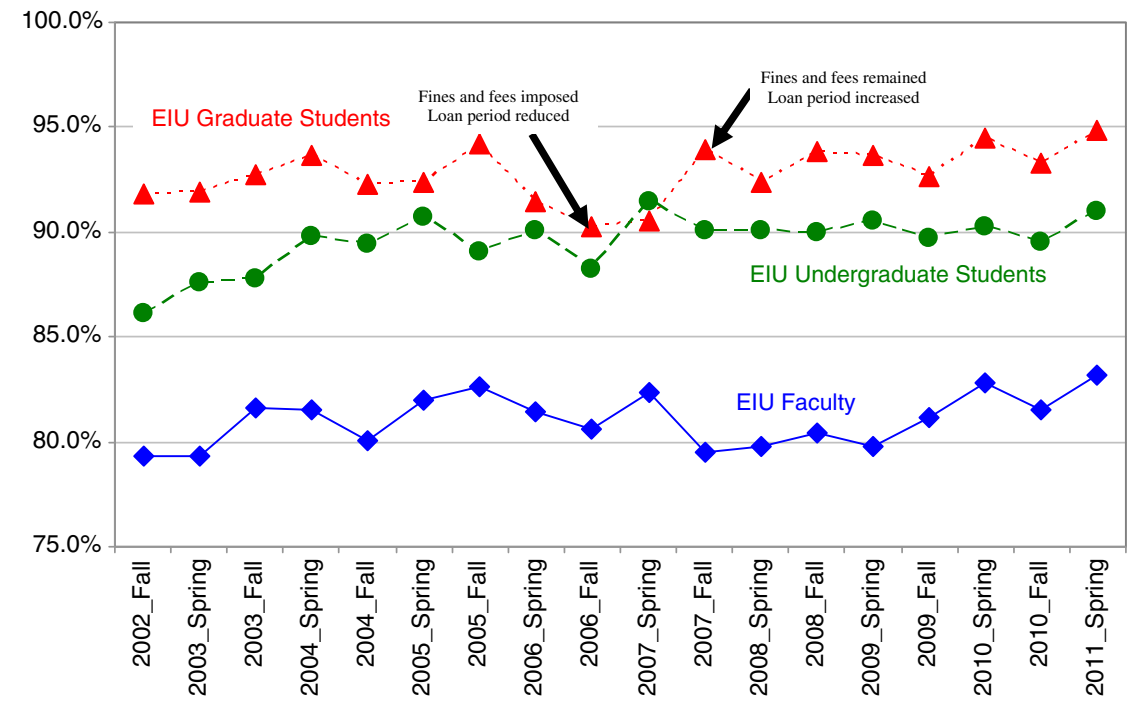

Graph 3. Eastern Illinois University patron's book return rate before due date. 


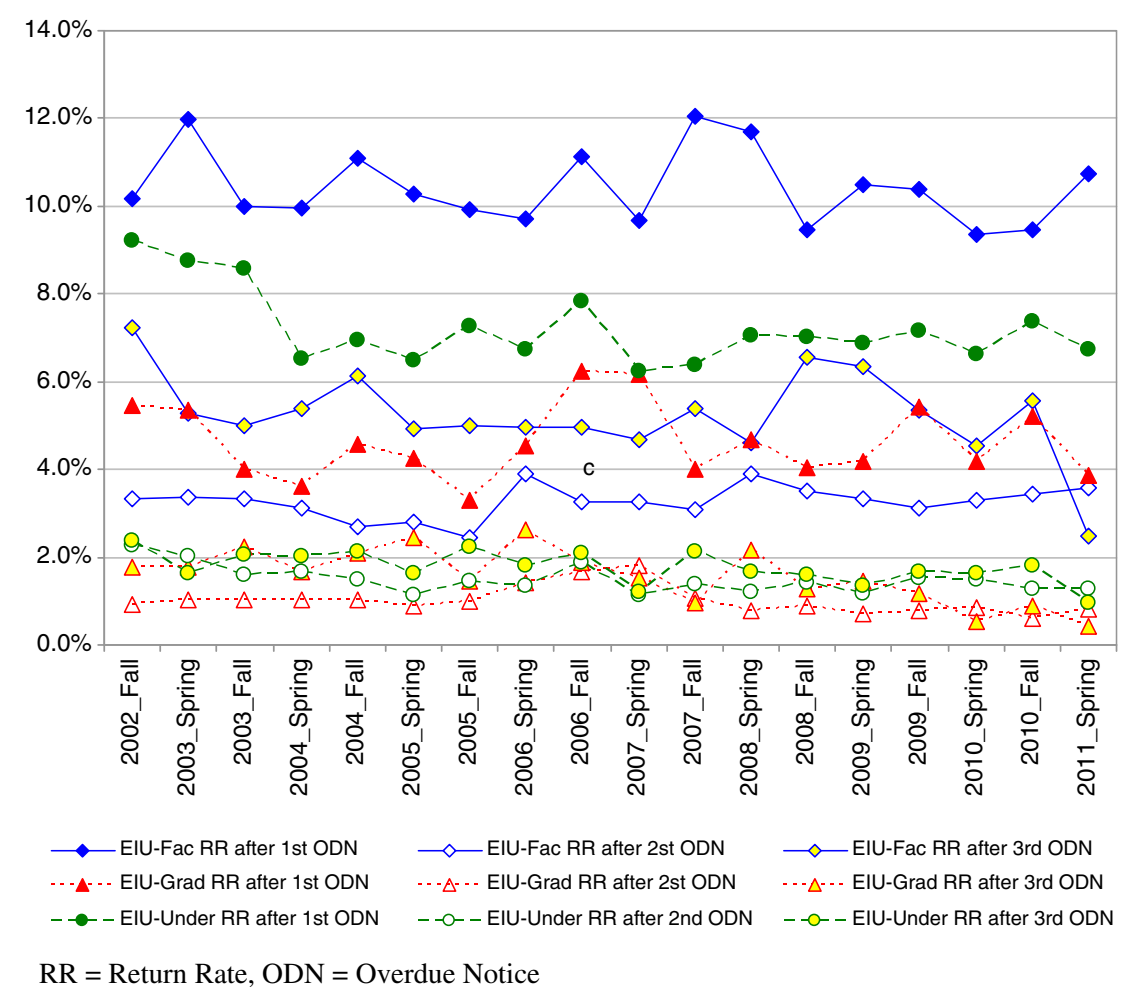

Graph 4. Eastern Illinois University patron's book return rate after due date.

\section{HYPOTHESIS 5}

UHM faculty's return rates before due dates are higher than that of EIU faculty. There is a distinct difference between these two groups. There is absolutely no penalty in returning books late for EIU faculty unless one actually has lost a book. On the other hand UHM faculty not only have fines for overdue books but also their online access to databases will be denied if they have fines over ten dollars. Thus, if there is a difference, it may be accounted for by the differences in fine policies between EIU faculty and UHM faculty.

The findings supported this hypothesis. On average $95.8 \%$ of books borrowed by UHM faculty between 2002 and 2011 were returned before due dates (Graph 6). UHM faculty returned 3.3\% after the first overdue notice and the last $1 \%$ returned after the second notice (see Table 2). In contrast, $81.1 \%$ of the books borrowed by EIU faculty in the same time frame were returned before due dates. EIU faculty returned $10.4 \%$ after the first overdue notice, $3.3 \%$ after the second overdue notice, and $5.2 \%$ after the third overdue notice (see Table 2 and Graph 6). Even though the initial return rates before due dates is only $81.1 \%$, approximately $95 \%$ of the books borrowed by EIU faculty were returned before they received their third overdue notice (see Table 2).

The difference in faculty return rates between these two institutions was statistically significant $(\mathrm{F}=1701, p=.000)$, meaning that the difference was not merely by chance. It is possible to conclude that fines make a difference in this particular group in regards to higher return rates before due dates.

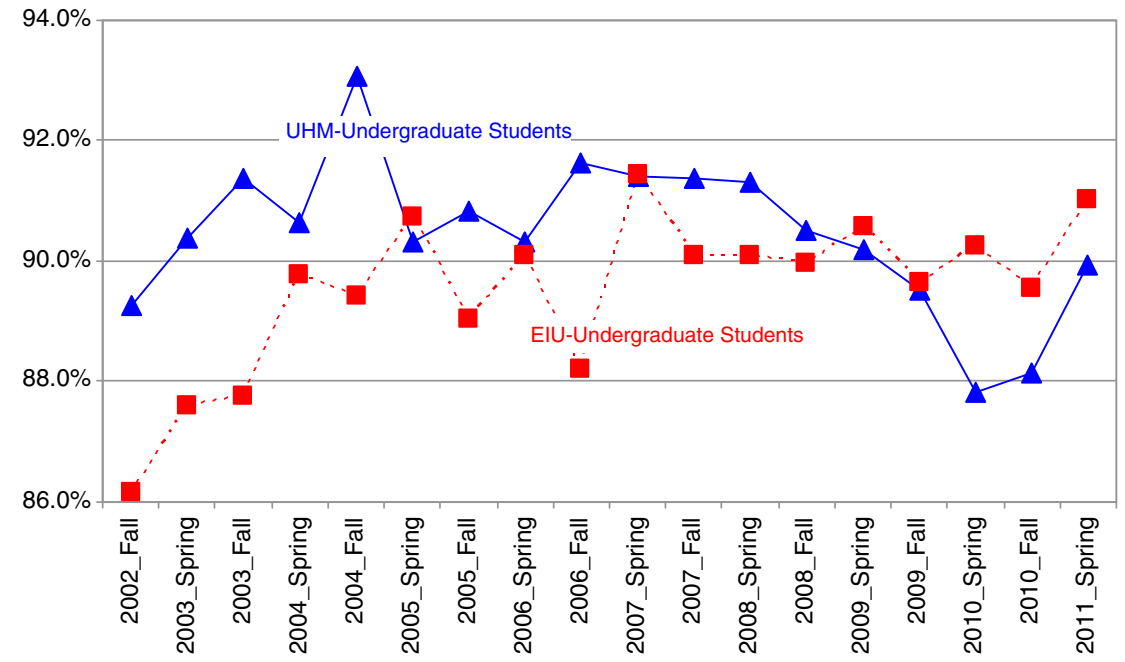

Graph 5. Comparison of undergraduate students return rate before due date. 


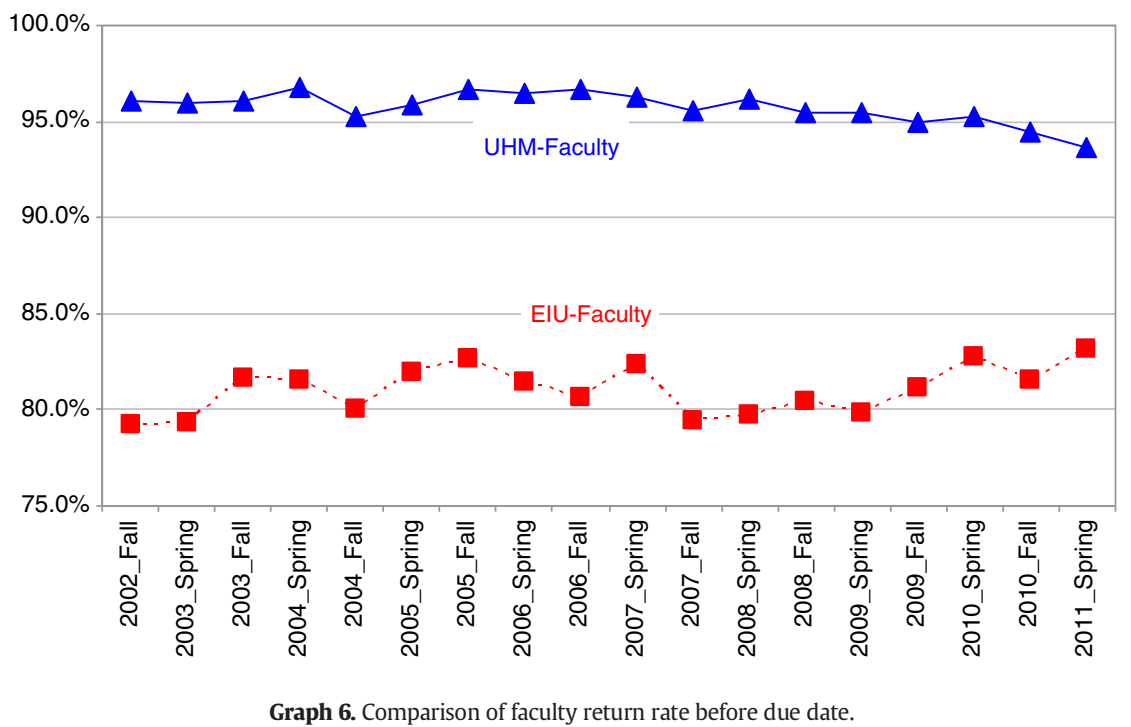

However, EIU faculty's return rates before due dates of $81.1 \%$ is still relatively high. This is voluntary and not affected by fines. There must be other factors that have an influence on the results. The courtesy notice may be an effective tool to encourage people to return books on time. Even though it may not be possible to test in this kind of study, there should be something that accounts for this relatively high initial return rate before due dates by EIU faculty when there is no penalty at all for returning books late, such as responsibility to the campus community, or ethics. Also, the effect of overdue notices cannot be overlooked: by the time EIU faculty received a third overdue notice, close to $95 \%$ of borrowed books were returned. Most of the remaining books are eventually returned to the library, with actual loss being very minimal.

Fines resulted in the 15\% higher return rates before due dates for UHM faculty than their counterparts. This $15 \%$ difference may be critical for the University of Hawaii at Manoa due to its remote geographical location. Because borrowing books is extremely costly, UHM tries its best to share available resources in the library before finding books outside the island.

\section{CONCLUSION}

The traditional operation of libraries is constantly being challenged due to ever-changing technological and societal developments. Lewis (2007) claimed that we are at the end of the print era. Lewis' recommendations in "The Strategy for the 21st Century Academic Libraries" included completing the migration from print to electronic collections and retiring legacy print collections. However, for now, many libraries still rely on print collections and current circulation systems. Thus, it is still important to find ways to share print resources with a maximum number of library users. Therefore, the present study regarding fine policy on patrons' book return behavior may lay the groundwork to help libraries choose their best options.

The data on return rates of borrowed books by different patron groups at EIU and UHM libraries were compared to determine whether fines had an impact on the patron's return behavior. The results indicate that fines indeed make a difference in patron book return behavior. Patrons who borrowed books under a fines policy returned books before due dates at a statistically significantly higher rate. As a result of this study, it is determined that a fines policy is an effective tool to ensure that books are returned on time and available to the maximum number of library users. While this study has determined that the imposition of fines does impact patron behavior in terms of the return of books, it in no way takes away from the contention that fines are harmful to the image of the library, a barrier to access, and that other approaches can be equally effective. Indeed, the results also support that the courtesy notices and overdue notices are effective in encouraging patrons to return books on time or to remind them of overdue books. Future areas of research could be to investigate the cost-benefit analysis of a fine system as administering a fine policy remains expensive or to complete a study on patron perceptions of fines.

\section{ACKNOWLEDGMENT}

John Whisler, Head of Cataloging Services at Eastern Illinois University, and Nackil Sung, Acquisition Head at the University of Hawaii at Manoa, helped generate the data used in this article.

\section{REFERENCES}

American Library Association (1996). Economic barriers to information access. www.ala.org/advocacy/intfreedom/librarybill/interpretations/economicbarriers (Retrieved May 2, 2012).

Ching, S. H., Tai, A., Pong, J., \& Cheng, M. (2009). Don't let micropayments penalize you Experience from the city University of Hong Kong. Journal of Academic of Librarianship, 35(1), 86-97.

Field, A. (2009). Discovering statistics using SPSS. London: Sage.

Lewis, D. (2007). A strategy for academic libraries in the first quarter of the 21st century. College and Research Libraries, 68(5), 418-434.

Mitchell, W. B., \& Smith, F. W. (2005). Using rewards to minimize overdue book rates. Journal of Access Services, 3(1), 47-52.

Mosley, P. A. (2004). Moving away from overdue fines: One academic library's new direction. Journal of Access Services, 2(1), 11-21.

Rupp, E., Sweetman, K., \& Perry, D. (2010). Updating circulation policy for the 21st century. Journal of Access Services, 7(3), 159-175. 